\title{
La presència de la immigració francesa al bisbat de Girona: una aproximació a partir de les Dispenses de Proclames (1593-1640)
}

French immigration in the diocese of Girona: an approach based on the "Dispenses de Proclames" (1593-1640)

La presencia de la inmigración francesa

en el Obispado de Girona: una aproximación a partir de las Dispenses de Proclames (1593-1640)

Arnau Barquer Cerdà ${ }^{1}$

\section{Resum}

El bisbat de Girona és una de les zones amb menys estudis pel que fa a la immigració francesa a l'edat moderna. La font de Dispenses de Proclames ofereix dades interessants per al seu estudi des de finals del segle xvi i inicis del xviI. Aquesta aproximació té la particularitat que es realitza des d'una font que abraça tot el territori i permet superar l'atomització dels registres parroquials. A partir del seu estudi, discutim la presència de la migració, la distribució territorial i la procedència dels immigrants. L'objectiu és oferir una visió complementària a altres fonts tradicionals i que permeti efectuar comparacions amb altres zones del Principat.

Paraules clau: Immigració francesa, Bisbat de Girona, Dispenses de Proclames, Edat Moderna.

\begin{abstract}
A study on French immigration in the Girona region is still needed for the early modern period. Marriages announced through Dispenses de Proclames ("Proclamation Waivers") give us new data to study this phenomenon. This source offers a different approach from that provided by parish registers, covering all the diocese and not just some parishes. Here-

1. ORCID: 0000-0002-1332-0754. Grup de Recerca en Història de les Societats Rurals de la Universitat de Girona. Correu electrònic: barquercerda.arnau@gmail.com.

Rebut: II/2021. Avaluat III/2021. Versió definitiva: V/2021.
\end{abstract}


by, we discuss the presence, territorial distribution, and settlement as well as origin of immigrants. These elements are all compared with other Catalan areas.

Keywords: French immigration, diocese of Girona, proclamation waivers, Modern Age.

\section{Resumen}

El Obispado de Girona es una de las zonas con menos estudios por lo que hace a la inmigración francesa en la edad moderna. La fuente de las Dispenses de Proclames ofrece datos interesantes para su estudio desde finales del siglo xv e inicios del siglo xvir. Esta aproximación tiene la particularidad que se realiza desde una fuente que abarca todo el territorio y permite superar la atomización de los registros parroquiales. A partir de su estudio, discutimos la presencia de la migración, la distribución territorial y la procedencia de los inmigrantes. El objetivo es ofrecer una visión complementaria a otras fuentes tradicionales que permitan efectuar comparaciones con otras zonas del Principado

Palabras clave: Inmigración francesa, Obispado de Girona, Dispenses de Proclames, edad moderna.

\section{Introducció}

Des de mitjan segle xx, diversos especialistes de les ciències socials s'han aproximat al fenomen de les migracions atesa la seva enorme importància durant la darrera centúria. La intuïció que guiava aquesta aproximació raïa en el fet que la seva explicació transcendia aspectes merament conjunturals i feia referència a processos vinculats amb el desenvolupament global de l'economia capitalista (Silvestre Rodríguez 2000). Això va servir com a revulsiu per als historiadors d'època moderna i contemporània - els va fer interrogar sobre els fenòmens migratoris en els seus camps d'estudi respectius - i per remarcar-ne la importància a l'hora d'analitzar processos com ara el desenvolupament de la indústria i el sorgiment del proletariat modern. Al mateix temps, també va servir als modernistes per donar compte de la vivacitat de les societats de l'Antic Règim, lleugerament emmascarada per una concepció estàtica de les comunitats agràries, on la mobilitat exercí un paper molt més quotidià del que s'ha considerat tradicionalment (Dupâquier, Sauvy i Le Roy Ladurie 1988; Possou 1988). En el cas català, un fenomen especialment rellevant i de notable interès historiogràfic ha estat el de la immigració francesa.

Com a fenomen característic de l'època moderna, la immigració francesa sobre el Principat de Catalunya fa temps que ocupa un lloc reconegut en la historiografia catalana. Des dels treballs de Jordi Nadal i Emili Giralt a inicis dels seixanta (Nadal i Giralt 1960), ${ }^{2}$ s'ha

2. Amb traducció catalana i revisió posterior a Nadal i Giralt, 2000. 
pogut resseguir l'impacte demogràfic i econòmic de l'espectacular arribada de joves provinents sobretot de regions de parla occitana ${ }^{3}$ a través de diverses zones del Principat, a partir de la tasca local i regional de molts historiadors.

El fenomen tingué de bon començament un enfocament demogràfic. En el seu treball seminal, Nadal i Giralt es preguntaven el perquè de la dualitat demogràfica existent a la Catalunya del segle xvin (accessible a través dels censos generals d'època borbònica). Van trobar en la immigració francesa un dels motius, si no el principal, per explicar la reeixida de la població catalana després de les malvestats baixmedievals. D'aquí que qualsevol estudi sobre el desenvolupament econòmic i social sobre la Catalunya moderna l'integrés com a factor a tenir en compte. ${ }^{4}$

Una de les regions que fins ara quedava per oferir una visió sobre el fenomen migratori és la del nord-est català, concretament el bisbat de Girona. Si bé s'han fet estudis parcials a partir d'algunes fonts com ara registres parroquials i els buidatges efectuats sobre la Matrícula de francesos de 1637, encara faltava un estudi sistemàtic de tota la regió. El buidatge i l'estudi d'una font fins ara inèdita, els llibres de confessions de les Dispenses de Proclames, ens ha donat la possibilitat de desenvolupar un estudi global per aquest bisbat que hem desenvolupat en el marc d'una tesi doctoral. ${ }^{5}$ En aquest article, la meva intenció és presentar les dades generals pel que fa a la temporització del fenomen i la seva distribució interregional per al període entre c. 1590-1640. Tot i que, en general, l'estudi confirma i aprofundeix en les dinàmiques generals establertes per Nadal i Giralt per al conjunt del Principat, hi ha alguns matisos a plantejar que ens recorden altra volta la necessitat d'endegar estudis comparatius. Aquests van en la línia que estudis recents han desenvolupat, ${ }^{6}$ a l'hora de subratllar l'impacte diferencial que tingué la immigració tant a l'interior com a la costa, així com pel que fa a ciutats i viles i pobles més petits i que ens remeten, en definitiva, al dinamisme dels processos econòmics i socials que es van donar a la Catalunya Vella durant el «llarg segle xvı». Deixem de banda l'elaboració d'un perfil dels immigrants i les vies d'integració en la societat d'acollida, que espero presentar aviat en un altre treball.

3. Sobre la nomenclatura dels «francesos» i la relació amb la seva procedència occitana, vegeu la nota al peu 14.

4. Així ho mostren les monografies regionals sobre desenvolupament econòmic i demogràic elaborades durant aquests anys per part de molts historiadors. Serveixin d'exemples els treballs de Jaume Dantí per al Vallès Oriental (Dantíi Riu 1986), Esteve Canyameres per a l'Occidental (Canyameres 1994), Alexandra Capdevila per al Maresme (Capdevila, 2003b), Jaume Codina i Carles Millàs per al Baix Llobregat (Codina 1988; Millàs i Castellví, 2005), Josep Cañabate per a la batllia de Miravet (Cañabate Fortuño 2018) i Maria José Vilalta per a la ciutat de Lleida (Vilalta 2003).

5. Dipositada a finals del 2018 i defensada davant tribunal el 20 de gener de 2019 a la Universitat de Girona sota el títol «Visch de mon treball i seguint los amos». Francesos i treballadors a la Catalunya de mas (Bisbat de Girona, ss. XVI $i$ XVII), la tesi ha estat dirigida per la professora Rosa Congost i realitzada al si del Centre de Recerca d'Història Rural, gràcies al gaudi d'una beca FI entre els anys 2015-2018.

6. Vegeu per exemple l'estudi de Jaume Dantí sobre el Vallès i d'Alexandra Capdevila sobre el Maresme, ja citats, i especialment el treball recent de Miquel Amengual per a l'àrea de Barcelona (Amengual Bibiloni i Pujadas-Mora 2016). 


\section{La immigració francesa a Catalunya i al bisbat de Girona}

Hi ha prou estudis locals per fer una valoració global del fenomen migratori en l'àrea del Principat, sobretot per les tendències generals que tenen a veure amb la temporització del fenomen i el seu impacte demogràfic a partir de la relació dels nuvis francesos respecte del total de matrimonis. Gràcies al corpus d'estudis actual, que no contradiu en gran mesura les aportacions que ja feren Nadal i Giralt, podem afirmar que la immigració francesa se circumscriu en la seva dimensió més àmplia des dels inicis del segle xvi fins a la primera meitat del xvir. Tot i que la presència de francesos la podem rastrejar a les fonts fins al començament del segle xviII, després de 1640 va ser molt més reduïda i amb uns perfils diferents, amb una vinculació més gran a professions especialitzades i als puixants circuits comercials de l'època (Salas Auséns 2009).

Entre els casos documentats en la Catalunya Vella, sens dubte l'àrea més estudiada, disposem de monografies i estudis locals al Baix Llobregat, Maresme, Empordà, Vallès i Plana de Vic. Pel que fa a la Catalunya Nova, tot i que amb un gruix d'estudis més prim, tenim treballs locals per a la ciutat de Lleida, Vilafranca del Penedès, Cervera, Reus, la batllia de Miravet i la Conca de Barberà.

Si bé el fenomen es podria circumscriure entre c. 1500 i c. 1650, com ja van assenyalar en un primer moment Nadal i Giralt, va passar per diverses fases d'arrencada, plenitud i declivi. Aquests períodes coincidiren amb els inicis del segle xvi fins el 1540, per al moment ascendent, entre 1540 i 1620 en el moment de plenitud i, a partir de 1620, amb el declivi, molt lligat a les conjuntures polítiques i econòmiques per les quals travessà la Corona Hispànica. ${ }^{7}$ Com hem anat comentant, aquests «ritmes» s'han confirmat en general en cada una de les àrees estudiades, principalment a partir de detectar-ne l'aparició en els registres parroquials de baptisme i de matrimoni, la font principal d'estudi de la immigració francesa en època moderna (Nadal i Giralt 2000; Planas 1985; Salas Auséns 1979).

Val a dir, però, i el cas de les comarques gironines així ho mostra, que el fet que els registres parroquials de matrimoni rarament siguin anteriors al darrer terç del segle xvi fa difícil traçar el recorregut que van marcar Nadal i Giralt només a partir d'aquesta font. Si bé les dades dels registres parroquials testimoniegen prou bé aquesta fase de declivi passada la segona meitat del segle xvil, com veurem en el proper apartat, sens dubte és obligat visitar altres fonts per acabar de copsar el fenomen en la seva extensió. Un exemple d'aquestes fonts alternatives són els registres notarials, que mostren, per exemple, com a la important vila de Castelló d'Empúries un 10,82\% dels individus presents en documents notarials durant el període 1555-1558 eren d'origen francès (Colls 2002c). Un altre és el de la coneguda Matrícula de francesos de 1637, una font que registra minuciosament els francesos habitants a les localitats costaneres, els quals mostren una presència encara important d'ultrapirinencs a finals del segle xv i inicis del xvi a l'Empordà (Capdevila 2011; Corredor i Plaja 2000).

7. Especialment a la crisi econòmica que precedí la Guerra dels Segadors i a l'esclat bèllic mateix que abraçà la dècada central del segle xvi (Torres i Sans 2006, p. 51-59). 
Els registres parroquials de matrimoni han permès també copsar el pes determinant que la immigració francesa tingué en moltes àrees, i que s'ha vinculat a la represa demogràfica posterior a la crisi baixmedieval, malgrat alguns matisos. Si bé es considera que la relació de nuvis francesos pel total de casaments se situa normalment entre el 10-20\%, aquest percentatge és molt variable en funció de les àrees estudiades, deixant de banda la divisió que ja establiren Nadal i Giralt entre l'interior i el litoral i el prelitoral. ${ }^{8}$

Els registres parroquials doncs, són una font imprescindible però no l'única a partir de la qual podem aproximar-nos a aquest fenomen. A part de les problemàtiques vinculades a la seva temporalitat, els registres també plantegen un problema en l'estudi regional del fenomen migratori. Com ja anunciava Miquel Planas en la seva valoració de la font per a l'Alt Empordà (Planas 1985), els registres parroquials plantegen algunes problemàtiques quan es vol fer-ne un ús comparat; tant per la seva dispersió, que fa que la disponibilitat sigui molt variable en funció dels avatars de cada municipi actual, com per la manca de sistematització: el registre es feia en funció de cada mossèn i, si bé hi ha alguns elements constants, quedava a criteri de cadascun d'ells la major o menor profusió de detalls.

Per tot això, la nostra aportació sobre la immigració francesa al bisbat de Girona es basarà tant en els registres parroquials de matrimoni com en les Dispenses de Proclames, una font fins ara inèdita ${ }^{9}$ en el període 1593-1640, i que s'ha mostrat molt interessant en alguns aspectes del fenomen. Especialment, en relació a mesurar l'impacte de la immigració al llarg del territori gironí, així com pel que fa a avaluar la procedència dels immigrants, un aspecte que rarament s'explicita en els registres parroquials. En algun punt de l'explicació també ens hem basat en les confessions de la Matrícula de Francesos de 1637, una font imprescindible per a l'aproximació a aquest fenomen, si bé en forma d'stock. ${ }^{10}$

\section{Les Dispenses de Proclames: una font original per a l'estudi de la immigració francesa}

Cal inscriure les Dispenses en el context d'ofensiva catòlica envers l'amenaça del protestantisme, que va tenir el seu esdeveniment més destacat en el Concili de Trento (15451563). Un dels aspectes que va abordar la revisió tridentina fou precisament el matrimoni (establert com a sagrament al Concili de Florència el 1458). Però no va ser fins llavors que es van establir els aspectes formals que hi donaven validesa canònica. Aquests es basaven

8. Així, tenim que un $60 \%$ dels immigrants presents en la Matrícula de Francesos de 1637 es troben establerts al Maresme (Capdevila 2003a; Nadal i Giralt 1966), de la mateixa manera que en zones on en general es detecta una presència important de nuvis francesos hi ha llocs amb baixa representació (casos de Sant Julià d'Altura (Canyameres 1994) i el Papiol (Millàs i Castellví 1996). Així doncs, el fenomen, en el conjunt del Principat, no fou homogeni.

9. Existeix una breu aproximació a l'obra de Joan Busquets (Busquets Dalmau 1994), on a partir de dades extretes de l'Arxiu Diocesà assenyala la font com un document interessant per a l'estudi de l'emigració francesa. Tanmateix, les dades que ofereix pel que fa al nombre de lligalls es queden curtes, segons hem comprovat un cop buidada la font.

10. Les dades de la Matrícula de Francesos les hem extret del nostre propi buidatge (ACA, Consell d'Aragó, Lligalls 551, Quadern 3) i provenen de les confessions escripturades des de Llançà fins a Blanes. 
en tres aspectes, la publicitat, la celebració i el consentiment patern que feien del matrimoni un fet legal (Ghirardi i Irigoyen López 2009). El primer aspecte, la publicitat, obligava a la realització d'amonestacions per informar al conjunt de la comunitat la realització del fet sagramental. A la pràctica, això es traslladava en el fet que a cada parròquia on els contraents haguessin habitat calia que el prevere anunciés durant tres diumenges consecutius la celebració de l'enllaç. En cada una d'aquestes amonestacions dominicals, els feligresos podien manifestar la seva disconformitat exposant l'existència d'impediments per a la celebració del matrimoni.

Aquest fet podia ser superat amb una dispensa, que havia de ser sollicitada a la seu diocesana, per tal d'evitar aquest procediment. En la seva sollicitud, el sollicitant (majoritàriament el nuvi, tot i que no és estrany trobar-hi dones) havia de demostrar que no reunia cap de les condicions considerades impediments (llargament detallades en les resolucions tridentines), sovint amb la declaració jurada de dos o més testimonis. Un cop donades les informacions, que podien fer referència a l'estat civil, l'ofici, la procedència i l'edat del sollicitant, el vicari general autoritzava la cessió de la dispensa sota la forma remissis monitionibus, cosa que l'habilitava per tirar endavant el matrimoni dins la legalitat eclesiàstica $\mathrm{i}$ «en fas de la Santa Mare Església».

L'ús de dispenses, però, no és un fet socialment estès en el bisbat de Girona fins entrat el segle XviI. En l'estudi de la sèrie que hem realitzat entre els anys 1593 i 1640, hem vist clarament una cesura que se situa a finals de la segona dècada del segle xvi i que ens deixa veure com la font va tenir una funció molt específica a finals del xvi. Aquesta fou la d'escripturar i regular els casaments realitzats pels nuvis provinents de bisbats del Regne de França. Precisament, la regulació dels casaments protagonitzats per estrangers fou una de les preocupacions del Concili de Trento, i així quedà plasmat en una de les seves sessions, concretament la XXIV i en el seu capítol VIIè, on alerta sobre els casaments d'homes «que vaguen» i la necessitat, per cautela, que es facin certes investigacions, així com l'obligatorietat que es casin amb una llicència. ${ }^{11}$

No tenim constància de cap edicte especial del bisbe de Girona pel qual s'obligui els pretendents d'origen occità a demanar dispenses per poder-se casar, però les disposicions del Concili de Trento, i el fet que els primers llibres que recullen les informacions demanades per atorgar llicències, facin menció explícita als francesos, ens permet deduir que en el seu inici aquest mecanisme va ser utilitzat pel bisbe de Girona per mantenir un cert control sobre la població nouvinguda. D'aquesta manera, fins a finals de la primera dècada del segle Xvir, a les cobertes dels llibres es poden llegir títols com liber informatiorum gallum o «llibre d'informació per casar-se francesos», entre altres exemples. Així doncs, en

11. «Muchos son los que andan vagando y no tienen mansión fija, y como son de perversas inclinaciones, desamparando la primera mujer, se casan en diversos lugares con otra, y muchas veces con varias, viviendo la primera. Deseando el santo Concilio poner remedio a este desorden, amonesta paternalmente a las personas a quienes toca, que no admitan fácilmente al Matrimonio esta especie de hombres vagos; y exhorta a los magistrados seculares a que los sujeten con severidad; mandando además a los párrocos, que no concurran a casarlos, si antes no bicieren exactas averiguaciones, $y$ dando cuenta al Ordinario obtengan su licencia para hacerlo.» El text és consultable a IntraText http://www.intratext.com/IXT/ESL0057/_P1C.HTM i el manuscrit a Biblioteca Digital Hispánica (f. 189). 
els registres que hem documentat que van de 1593 a 1620, aproximadament, hi ha una altíssima representació de nuvis francesos com no hem vist que existeixi en cap altra font que faci referència a aquest contingent poblacional en el bisbat de Girona, que tendí a disminuir mentre es donaven dos factors. Per una banda, el progressiu descens del fenomen migratori a partir de les primeres dècades del xvi i, per l'altra, l'inici de l'ús cada cop més estès per part de la població del bisbat de Girona de les dispenses com a tràmit per a la contractació matrimonial (vegeu el gràfic 1), fins al punt que un percentatge molt important de casaments es devien fer mitjançant dispensa. ${ }^{12}$

Al llarg del període 1593-1640, hem recomptat un total de 5.553 expedients que conformen una sèrie quasi seguida, tan sols interrompuda per la no conservació dels documents d'alguns anys. Com es pot observar al gràfic 1 , el nombre absolut de dispenses registrades en els llibres de l'Arxiu Diocesà augmenta considerablement a partir de la segona dècada de 1600 fins a situar-se als nivells que ben entrat el segle xvir i sobretot al xviI assolí l'ús d'aquest mecanisme.

Gràfic 1

Total de nuvis francesos i total d'expedients de dispenses per any (1593-1640)

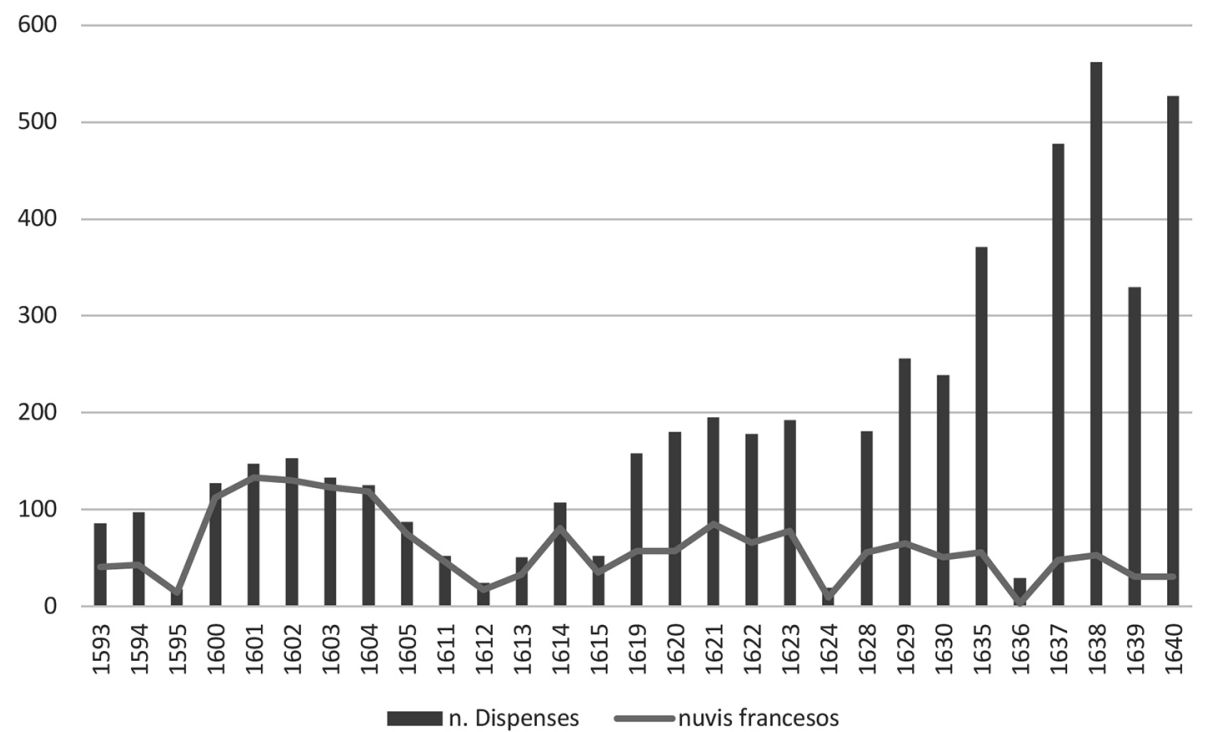

Font: ADG, Dispenses de Proclames.

12. Així ho testimoniegen Congost i d'altres (2013), on afirmen que els segles xvII i xIx els matrimonis efectuats amb dispenses podien representar entre un $70-75 \%$ del total. 
D'aquesta manera, tenim un bon corpus de les sollicituds que els nuvis feien davant de l'escrivà i que ens ofereixen un conjunt d'informacions molt valuoses per aproximar-nos de manera quantitativa i qualitativa als immigrants francesos del conjunt del bisbat de Girona. Principalment, se'ns dona informació sobre el lloc de procedència, l'ofici desenvolupat, el lloc de residència actual i, sovint però no sempre, l'edat d'arribada. En funció de qui prengués declaració i sobretot durant els primers anys, és freqüent trobar relacions extenses en què el sollicitant i els seus testimonis donen informació sobre la vida del futur nuvi des que va arribar, els llocs de residència i de treball previs, si era casat o no a França, o fins i tot els trajectes que havia fet en algun moment a la seva parròquia de procedència. La nostra voluntat ha estat la de poder sistematitzar el gran nombre d'informació disponible, però en molts casos ha resultat impossible atesa l'heterogeneitat de les declaracions.

En aquest treball, però, hem fet servir les Dispenses, juntament amb els registres matrimonials, per donar una visió general del fenomen migratori en el conjunt del Bisbat de Girona, per això ens hem centrat en les dades relatives al ritme demogràfic i a un element que considerem molt més interessant, com és la distribució territorial dels nuvis francesos.

\section{Ritme i presència de la immigració al bisbat de Girona. 1590-1640}

A partir de la font de Dispenses de Proclames, hem pogut identificar 2.767 francesos entre nuvis, testimonis i pares al llarg de la sèrie que va des de 1593 (el primer any en què disposem de les dispenses) al 1640. Tal com s'ha fet en la resta d'estudis sobre la immigració francesa, hem plantejat situar aquest nombre al llarg del temps per fer-nos una idea del ritme de la immigració i veure si s'adiu a la tendència assenyalada per al conjunt del Principat. Els resultats obtinguts plantegen una forta presència de francesos durant la darrera dècada del xvi i la primera del xviı. Va ser a partir de llavors que la presència de francesos en termes absoluts dins la font de dispenses fou cada cop més reduïda, tot i que no desaparegué del tot.

Però tal com dèiem en el punt anterior, en els seus inicis les dispenses són demanades principalment per nuvis francesos. Així, segons el gràfic 1, percentualment prop del 90\% dels nuvis que demanen dispenses entre els darrers anys del segle xvi i els primers del xvII (grosso modo entre el 1593 i el 1605) són de procedència ultrapirinenca. Aquesta tendència es veu progressivament invertida, amb l'aparició de cada cop més nuvis catalans, sobretot a partir de la segona dècada del segle xvir. A partir d'aquest moment, i coincidint amb l'època en què l'ús de dispenses sembla que es dispara, a la font hi trobarem representada sobretot la població local.

Preses globalment, les dades no deixen cap dubte que el ritme que seguí la presència de francesos al bisbat de Girona segueix la tendència assenyalada per Nadal i Giralt i la majoria d'estudis ulteriors. Queda reflectit el moment d'auge en el tombant del segle xv al XvII (la qual cosa explicaria la gran presència de nuvis entre les dècades de 1600-10 i 1610-20) i el posterior declivi de la presència de francesos a partir de 1620. 
De fet, el buidatge dels llibres de matrimonis de 6 parròquies ${ }^{13}$ de tots els anys que van entre l'inici del segle xvi fins al 1640 ens mostra una evolució força semblant a la que veiem a les Dispenses pel que fa a la presència de francesos, ${ }^{14}$ amb un ascens de comptabilitzacions que detectem a partir de 1590 i descens a partir de 1620 (taula 1).

\section{Taula 1}

\section{Total de casaments de nuvis francesos entre 1601-1640 en les parròquies d'Amer, Banyoles, Besalú, Cassà de la Selva, Castelló d'Empúries i la Bisbal d'Empordà}

\begin{tabular}{|l|l|l|l|l|l|}
\hline Parròquia & $1601-1610$ & $1611-1620$ & $1621-1630$ & $1631-1640$ & $\mathbf{1 6 0 0 - 1 6 4 0}$ \\
\hline Amer & $63,(1)$ & $54,(0)$ & $87,(3)$ & $56,(4)$ & $\mathbf{2 6 0}(\mathbf{8})$ \\
& $2 \%$ & $0 \%$ & $3 \%$ & $7 \%$ & $\mathbf{3 \%}$ \\
\hline Banyoles & $85,(15)$ & $82(14)$ & $86(6)$ & $32(0)$ & $\mathbf{2 8 5}(35)$ \\
& $17,6 \%$ & $17,1 \%$ & $7 \%$ & $0 \%$ & $\mathbf{1 2 , 3 \%}$ \\
\hline Besalú & $86,(6)$ & $54(1)$ & $115(3)$ & $64(2)$ & $\mathbf{3 1 9 ( 1 2 )}$ \\
& $7 \%$ & $2 \%$ & $3 \%$ & $3 \%$ & $\mathbf{4 \%}$ \\
\hline Cassà de la Selva & $49,(5)$ & $66(6)$ & $49(1)$ & $38(0)$ & $\mathbf{2 0 2}(\mathbf{1 2})$ \\
& $10 \%$ & $9 \%$ & $2 \%$ & $0 \%$ & $\mathbf{6 \%}$ \\
\hline Castelló d'Empúries & - & $156(50)$ & $170(33)$ & $105(19)$ & $\mathbf{4 3 1}(\mathbf{1 0 2})$ \\
& & $32 \%$ & $19 \%$ & $18 \%$ & $\mathbf{2 4 \%}$ \\
\hline La Bisbal & $49,(14)$ & - & $15(4)$ & $188(13)$ & $\mathbf{2 5 2}(31)$ \\
& $29 \%$ & & $27 \%$ & $7 \%$ & $12 \%$ \\
\hline
\end{tabular}

Font: ADG, registres parroquials. Entre parèntesis i en cursiva, el total de nuvis francesos, el percentatge és el de matrimonis francesos sobre el total.

Un descens, però, que s'inicia una dècada abans si en el mateix còmput de parròquies excloem Castelló d'Empúries, de bon tros la parròquia amb més presència d'immigrants (recordem el potencial demogràfic de la vila fins i tot a inicis del segle xviI) i que exerceix una forta influència sobre el total de la mostra. Tot i així, sense Castelló, sembla clar que després del pic de matrimonis de finals del segle xvi i primers anys del xvi la presència de francesos va anar disminuint, segurament afectant més les petites parròquies rurals que no pas les viles amb una economia més diversificada com seria el cas de l'antiga capital del comtat d'Empúries. Així doncs, si bé pot resultar complicat afirmar que és a partir de finals

13. Una selecció d'una primera prospecció feta sobre 14 parròquies entre els períodes 1600-1610 i 1630-1640. Aquesta primer sondatge va servir per descartar una variació en el total de matrimonis que pogués distorsionar la mostra i les conclusions. Aquestes parròquies van ser les d'Amer, Banyoles, Besalú, Cassà de la Selva, Calonge, Camós, Castelló d'Empúries, Celrà, la Bisbal, Sellera de Ter, Llançà, Peratallada, Sant Feliu de Boada i Verges. El total de matrimonis entre 16001610 és de 833 i, entre 1630-1640, de 834. Així doncs, el total de matrimonis roman estable i ens permet traçar conclusions per a tot el període.

14. Com és habitual, s'han identificat com a francesos els registres on el nuvi duia l'etiqueta de frances o gascho. 
del xvi que hi ha un pic important en els casaments de francesos (la majoria de registres s'inicien llavors), no ho és tant determinar-ne els anys de menor presència i, com hem vist, d'esllanguiment del corrent migratori cap a la segona dècada del xviI.

En resum, doncs, les Dispenses de Proclames segueixen la tendència que trobem també als registres parroquials, a partir de la qual podem afirmar clarament que la immigració francesa en el conjunt del bisbat va viure el seu moment de plenitud entre la segona meitat del segle xvi i les primeres dècades del xviı, i començà a declinar després de 1620 (amb repunts ocasionals), res massa allunyat de les dades que referíem més amunt per al conjunt del Principat.

Alhora, la presència de nuvis francesos va tenir un pes similar al documentat en el conjunt del Principat pel que fa al total dels matrimonis. Si bé les Dispenses no ens permeten aquesta comparativa atès que es tractava d'un registre amb una presència molt reduïda de «naturals» fins ben entrat el segle xvir, els registres parroquials mostren percentatges entre el $10 \mathrm{i}$ el 20\% de nuvis francesos sobre el conjunt (vegeu la taula 1), tal com hem assenyalat per al conjunt del país. Fins ara, el bisbat de Girona no s'escapa de les tendències generals que ja hem destacat al Principat.

Ara bé, com es pot veure a la taula 1 pel que fa als registres parroquials, aquest percentatge no fou pas el mateix a tot arreu. Atès que les dispenses ens permeten una aproximació sobre el conjunt del bisbat, què ens diuen en relació a la distribució dels francesos?

\section{Assentament i distribució territorial de la immigració en el bisbat de Girona}

El bisbat de Girona cobreix les actuals comarques de l'Alt i Baix Empordà, Gironès, Pla de l'Estany, Garrotxa, la Selva, l'àrea septentrional del Maresme i la zona oriental del Ripollès, és a dir, un territori extens i heterogeni. Tot i que segons les tesis que es desprenen de l'estudi de Nadal i Giralt es podria dir que la immigració era present a tot arreu del territori català, és sabut -i les dades disponibles per al conjunt del Principat així ens ho mostrenque els percentatges de representació de l'emigració varien entre diverses zones geogràfiques. Tampoc creiem que no ho fos dins de zones com el bisbat de Girona, amb una realitat demogrànica i socioeconòmica diversa, i per això hem cregut convenient estudiar la distribució dels francesos en cada una de les àrees que formaven el bisbat. Som conscients que l'ús de comarques no seria el més adequat per a una aproximació històrica rigorosa a les diverses realitats socials i geogràfiques que componien el bisbat. Però una aproximació d'aquesta mena requeriria treballs previs que determinessin les àrees o zones amb prou relació geogràfica, social i de població que es correspongués a les formes de poblament i explotació del medi per al període que ens ocupa. Aquest treball encara resta per fer, així que no hem tingut més remei que utilitzar les comarques actuals per delimitar, grosso modo, espais prou diferenciats que han mantingut les seves particularitats fins avui dia. 
En el nostre estudi, hem pogut comprovar que, principalment, la presència de nuvis francesos documentats en els llibres de Dispenses es troben distribuïts entre la ciutat de Girona i el seu binterland i les comarques de l'Alt i el Baix Empordà.

Per al total de nuvis francesos, entre els anys 1593-1640 trobem una distribució per comarques en què l'Alt Empordà se situa al capdavant amb un 34\% dels nuvis, seguit pel Gironès amb un 26\%, tot seguit el Baix Empordà (14\%), la Selva (11\%), la Garrotxa i el Maresme (ambdues amb un 5\%), el Pla de l'Estany (3\%) i finalment el Ripollès amb un 2\% (vegeu el mapa 1). Cal tenir en compte que les comarques del Maresme i el Ripollès, en formar part tan sols parcialment del bisbat de Girona, es veuen subrepresentades dins el conjunt de dispenses, i així mateix la seva contribució en l'acollida dels nouvinguts (i més si tenim en compte que un nucli tan important i ben estudiat com Mataró queda fora del nostre estudi).

\section{Mapa 1 \\ Distribució percentual per comarques actuals del nombre de nuvis francesos obtingut de les Dispenses}

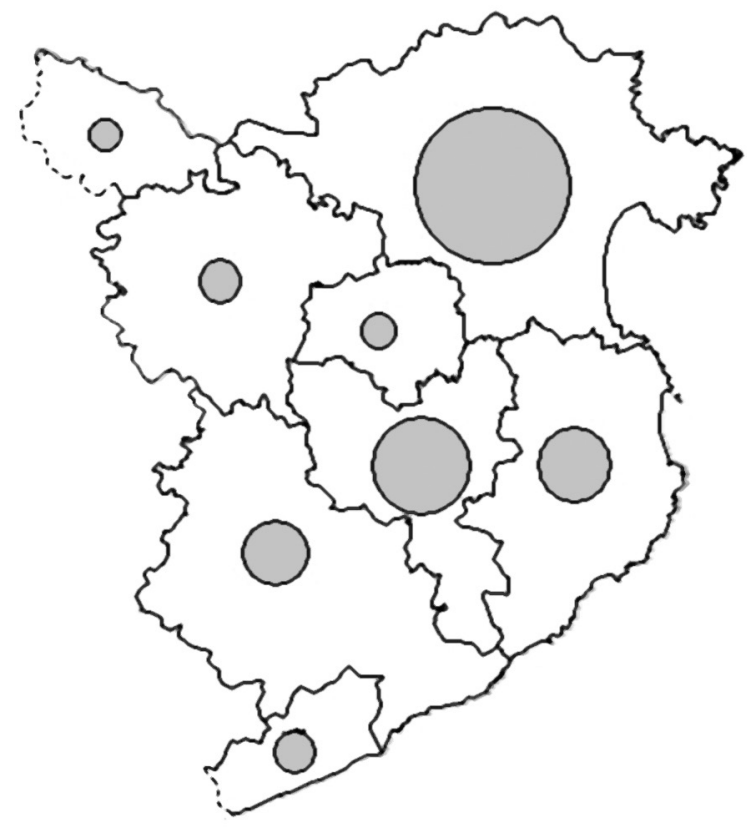

Font: ADG, Dispenses de Proclames.

Com és això? A priori caldria remarcar que a mitjan segle xvi són precisament la zona empordanesa i el Gironès (comprenent també el Pla de l'Estany) les zones més poblades del bisbat a partir de les dades del fogatge de 1553 , que ens dona el total de focs per a cada una de les comarques actuals (taula 2). 
Taula 2

Total de focs, densitat $\mathbf{i}$ habitants en cada una de les comarques de la regió de Girona

\begin{tabular}{|c|c|c|c|}
\hline \multicolumn{4}{|l|}{ Fogatge de 1553} \\
\hline & focs & focs per $\mathrm{km}^{2}$ & conversió a hab \\
\hline Alt Empordà & 3141 & 2,8 & 15.705 \\
\hline Baix Empordà & 3203 & 5,5 & 16.015 \\
\hline Garrotxa & 1734 & 2 & 8.670 \\
\hline Gironès (+ PdE) & 3691 & 5,2 & 18.455 \\
\hline Selva & 2032 & 2,5 & 10.160 \\
\hline
\end{tabular}

Dades extretes de Nadal i Giralt, 2000. Hi hem afegit la darrera columna d'habitants totals multiplicant el nombre de focs per 5 com a convertidor.

Així doncs, caldria preguntar-se: la font de Dispenses de Proclames té sobrerepresentats els matrimonis provinents de les zones més habitades del territori? En aquest punt entren en valor les dades obtingudes a partir dels registres parroquials, que ens serveixen de contrast per a zones més concretes. Així doncs, en el cas de Banyoles (Pla de l'Estany) hem documentat la presència de més d'un 10\% de nuvis francesos en el conjunt de matrimonis entre 1600-1640. D'aquesta manera, la presència relativa de nuvis francesos en l'àmbit parroquial difereix de les dades obtingudes per a les dispenses, a partir de les quals podríem concloure, per exemple, que la presència de francesos al Pla de l'Estany va tenir un impacte quasi testimonial, mentre que les dades obtingudes des del registre parroquial de matrimonis de Banyoles confirma que es tracta d'una presència important i més durant els primers decennis (vegeu la taula 1) quan documentem percentatges que ronden el 17\% (els decennis posteriors, fins al 1640, les dades són solidàries amb la tendència general i tenim un descens sostingut de nuvis ultrapirinencs fins a no trobar-ne cap).

Sembla evident que les zones més habitades, com ara viles i ciutats, van exercir una major atracció pel que fa al fenomen migratori. L'existència d'una economia més diversificada i les necessitats d'uns sectors determinats com ara el tèxtil o la construcció en una fase expansiva com és la que va de 1550 a $1650^{15}$ podrien explicar que bona part del corrent migratori s'hi dirigís, com han anunciat els treballs recents (Amengual Bibiloni i Pujadas-Mora 2016; Capdevila 2014). En el conjunt del bisbat de Girona, el cas de l'Alt Empordà, amb les dades ja exposades, sembla que s'adiu bé a aquesta explicació si tenim en compte la presència de poblacions que destaquen pel seu poblament i potencial productiu durant la baixa edat mitjana i l'edat moderna, com són els casos de Castelló d'Empúries, Figueres

15. En el cas de Girona, tenim els treballs de Narcís Castells i Ramon Alberch (Alberch i Fugueras 1984; Castells 1994) en relació a l'activitat gremial, sobretot centrada en la construcció. 
o Peralada. ${ }^{16}$ Però, van ser aquestes viles les que van concentrar el gruix de l'emigració? És present en àrees de poblament més dispers?

Si agafem les dades obtingudes a partir de la font de Dispenses, i en veiem la distribució en les parròquies altempordaneses en el període de més afluència d'immigrants francesos (és a dir, entre el 1593 i el 1620), podem constatar que el conjunt de les viles de Castelló d'Empúries, Peralada, Figueres i Roses ${ }^{17}$ aglutinen un 33\% dels nuvis ultrapirinencs que solliciten dispensa. El restant $67 \%$, doncs, es distribueix per la resta de parròquies de la comarca, les quals suposen cada una entre l'1 i el 3\% del conjunt de francesos identificats a l'Alt Empordà. Així, una vila com Castelló d'Empúries reuní el 13\% d'immigrants de la comarca, una dada important, però que ens impedeix afirmar que la immigració era un fenomen específicament urbà o en tot cas sense presència més enllà de les poblacions més habitades. En el cas de l'Alt Empordà, més de la meitat dels francesos es van establir (estem parlant en tot cas de casaments, cal recordar-ho) en zones de poblament dispers.

Precisament el cas contrari ens el dona altra vegada el Pla de l'Estany, on quasi el 55\% dels immigrants que demanen dispensa afirmen residir a la vila de Banyoles. Així doncs, i tenint en compte les dades provinents dels registres parroquials i que hem exposat més amunt en la taula 1, la presència al Pla de l'Estany, tot i ser notable en termes relatius, se circumscriu sobretot a aquesta població, i té un impacte molt menor en les àrees més disperses que el que semblaria per a l'Alt Empordà. El cas paradigmàtic de la distribució territorial enmig d'un sistema urbà ens el dona la ciutat de Girona i el seu territori; quasi un $65 \%$ dels francesos presents al Gironès en aquest període de plenitud es troben establerts a la ciutat. Aquestes dues realitats, que suposen un element interessant per remarcar comportaments diferenciats pel que fa a les tendències d'assentament de la immigració en una mateixa regió com és el bisbat de Girona, les hem representat gràficament en el mapa 2.

Un cop plantejada la distribució de la immigració en el període de més gran auge immigratori, cal veure què passa en el moment immediatament posterior, que en la nostra sèrie correspon als anys que van de 1620 a 1640. Tal com hem plantejat més amunt, és en aquestes dues dècades que el fenomen immigratori comença a declinar, i això podria afectar en la manera en què els francesos es distribueixen pel territori, donant peu a fenòmens de concentració o de dispersió.

A partir d'una anàlisi comarcal com fins ara, hem pogut detectar comportaments diversos que ens permeten afirmar que, efectivament, es van donar alguns canvis d'un moment a un altre. Pel que fa a les comarques de l'Alt Empordà i el Gironès, veiem repetits els mateixos patrons que en el període 1593-1620. Això és, una àmplia dispersió pel territori en el cas altempordanès i una acusada concentració de la població francesa al voltant de la ciutat de Girona en el cas de la comarca del Gironès. A l'Alt Empordà hem detectat, això, sí, un descens generalitzat dels percentatges d'ultrapirinencs situats en les poblacions de més concentració poblacional (c. 200 focs el 1553) respecte el total de tota la comarca;

16. Pel que fa a la seva evolució, especialment en el cas de Castelló d'Empúries, són d'obligada consulta els treballs de Josep Colls (Colls 2002a 2007).

17. Les 4 poblacions que s'aproximen molt o depassen els 200 focs segons el fogatge de 1553. 


\section{Mapa 2 \\ Distribució de cada un dels registres de nuvis francesos per parròquies (un punt, un registre)}

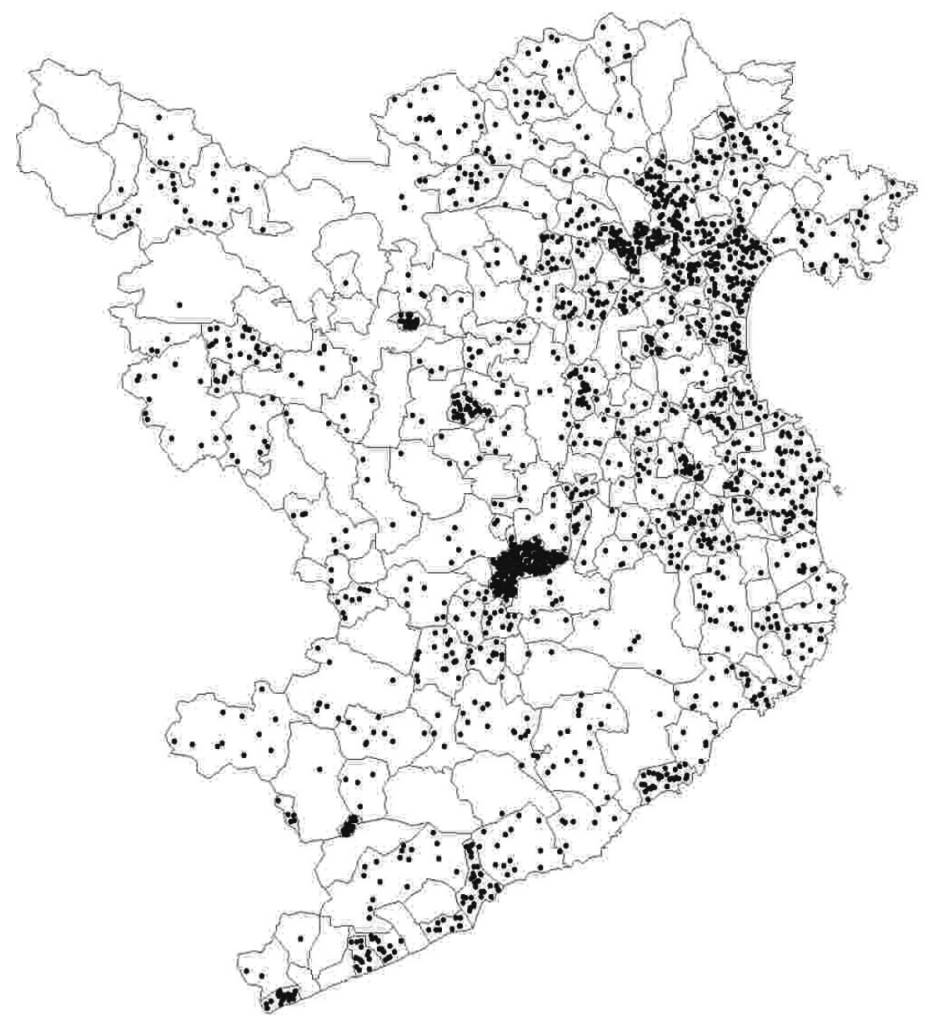

Destaca la concentració de registres a la ciutat de Girona i els nuclis de Banyoles i Olot, mentre que la zona empordanesa apareix molt més disseminada. Font: ADG, Dispenses de Proclames.

quelcom que interpretem com una caiguda general en el moment de declivi immigratori. En el cas de Girona, aquest fet és més acusat i el descens percentual deixa en un 4\% la relació de francesos respecte del total de gironins identificats per les Dispenses. Assumim aquesta dada com a indicador d'un gran descens de la presència francesa a la ciutat partint de la premissa que a partir de 1620 l'ús de les dispenses s'ha estès per tot el bisbat i per part de tothom, per la qual cosa és una font representativa del total de matrimonis (Congost, Portell, Saguer i Serramontmany 2013).

Les comarques del Baix Empordà i la Selva mostren comportaments semblants. Els percentatges de francesos també baixen molt, però com en el cas del Gironès i l'Alt Empordà 
es manté la mateixa distribució territorial. També es documenta una pèrdua percentual pel que fa a la distribució en unes viles determinades com ara Blanes, que passa d'aglutinar el 22\% de francesos de la Selva a només un 12\% o Torroella de Montgrí, que del 21\% passa al $7 \%$ entre 1620-40. Un fet que contrasta amb el guany en termes relatius pel que fa al nombre d'ultrapirinencs d'ambdues comarques per part d'altres viles, com ho serien els casos de la Bisbal i Hostalric, que passen, respectivament, d'un 5\% a un 21\% i d'un 14\% a un $18 \%$.

Altres casos que assenyalen un canvi entre ambdós períodes són els del Pla de l'Estany i la Garrotxa. En aquests, les viles que havien exercit d'importants pols d'atracció per als immigrants durant els anys d'auge, al llarg del període 1620-40 no depassen un 3\% de representació del total de francesos presents en aquestes comarques. El cas de Banyoles és altament significatiu, atès que durant el període anterior més del 50\% d'immigrants del Pla de l'Estany provinents de França afirmaven residir-hi. El mateix podem afirmar en els casos d'Olot i Besalú. A tall d'hipòtesi, tan sols podem plantejar que el retrocés del flux migratori va afectar molt més zones no tan potents demogràficament i més allunyades dels grans pols econòmics del territori gironí.

\section{Les àrees de provinença dels immigrants}

Com ja hem apuntat en parlar de les Dispenses, un element present en les relacions dels nuvis que hi fan declaració és la referència a la zona de procedència, concretament el seu bisbat d'origen (i molt menys, la població). Així, d'un total de 2.750 individus identificats (entre nuvis i testimonis), 1.669 confessen el seu bisbat de naixement.

Les àrees de procedència dels immigrants comprenen diverses regions del territori històric que coneixem com Occitània, territori abstret que en el període estudiat es troba des de fa temps subjecte sota el domini de la Corona Francesa i és part integrant del Regne de França; d'aquí que principalment les referències contemporànies des dels llocs d'assentament d'aquests individus parlin de francesos, més que no pas d'occitans, malgrat que aquest seria l'apellatiu corresponent a partir dels trets culturals i lingüístics dels nouvinguts. ${ }^{18}$ En comptes d'això, es tindrà sempre present la seva subjecció al monarca francès, malgrat que molts d'ells hauran passat més temps de la seva vida sota domini de la Monarquia Hispànica i els seus regnes que no pas sota el domini de la corona francesa.

18. «Dit això, què significa altra vegada "francesos"? Òbviament, i no em cansaré de repetir-ho perquè la historiografia sovint els ho nega, són subjectes del rei de França, però són de naturalesa o de nació no francesa; en tot cas, són de civilització i de llengua occitana, i més aviat de dialecte gascó. Per això cal interessar-me pel lloc de procedència d'aquests occitans, i aproximar-me a una geografia de l'emigració» (Peytaví Deixona 2010, p. 279). Estem molt d'acord amb J. Peytaví en aquest aspecte, però per altra banda l'existència d'una identitat «occitana» és segurament discutible; per això hem cregut més rigorós referir-nos als nouvinguts com a «francesos», que és com els defineixen les fonts consultades, sense que això vagi en contra de ressaltar quan faci falta les particularitats ressenyades per Peytaví i altres autors. Com bé diu O. Jané, mai en aquella època es va fer referència a Occitània com a tal, i l'ús del terme, sense els matisos adequats, cauria en l'anacronisme (Jané Checa 2009). 
La regió francesa, però, no comprèn ni ara ni llavors un territori homogeni. Les diverses característiques del clima i l'orografia, així com les particulars evolucions de cada territori van donar peu a zones amb un caràcter propi, les quals en el detall van generar condicions específiques que van afavorir el procés migratori. A conveniència de determinar les diferents causes i les raons del fenomen de l'emigració, Nadal i Giralt van fer una proposta de categorització que ha tingut èxit entre els i les investigadores posteriors. En aquesta proposta partien l'àrea d'irradiació en tres parts que resseguien de sud a nord tot el territori occità: començant pels Pirineus i les valls properes, les terres del Llenguadoc resseguint el pas del riu Garona i finalment la zona dels Massissos Centrals.

Pel que fa a la majoria d'estudis sobre immigració francesa a Catalunya, coincideixen a assenyalar l'àrea pirenaica i circumpirinenca com la zona que més aportacions fa al corrent migratori. L'explicació més plausible sembla que és la proximitat geogràfica, ja que parlem de territoris adjacents, i si tenim en compte les continuades relacions entre les valls pirinenques i la participació dels circuits comercials sembla lògica la seva major presència en els diversos registres que comptabilitzen immigrants. ${ }^{19}$

Les dades obtingudes per al bisbat de Girona a partir de les Dispenses ens mostren una aclaparadora majoria d'immigrants (nuvis i testimonis) procedents dels bisbats de la zona septentrional, sobretot durant la primera dècada del segle xvII, que és el període en què en documentem més. Aquesta zona pertany a la categoria que Nadal i Giralt van definir com la de les Terres Altes i Massissos, la qual fa referència sobretot a l'Alta Alvèrnia, el Baix Carcí i el Gavaldà o Gévaudan. Les informacions obtingudes de les Dispenses corresponen als bisbats d'Angulema, Caurs, Llemotges, Mendes, Perigús, Rodés, Sant Flor, Sarlat i Tula. A la taula 3 hem representat els nombres absoluts de nuvis per bisbat i en tant per cent sobre el total de la regió que representen. Al mapa 3 hi ha la representació dels bisbats i la representació segons el total de nuvis que en procedeixen.

En termes percentuals, pel que fa al total de nuvis que confessen el bisbat de procedència, 380 (26,55\%) afirmen provenir de bisbats dels Pirineus; 419 (29,28\%) de la zona del Llenguadoc i la conca de la Garona i 632 (44,16\%) de les muntanyes dels Massissos Centrals.

Pel que fa a la zona pirinenca, el bisbat més representat és el de Comenge (que representa un 27,21\% per aquesta regió), seguit per Tarba, Coserans, Mirapeix, Rius i Pàmias. Comenge, però, hi té una enorme presència amb més del doble de mencions que les diòcesis d'aquesta zona, cosa que no ens sorprèn, atès que per les referències que en tenim dels estudis previs, és el bisbat més present en fonts com ara la Matrícula de 1637 o els registres hospitalaris (Nadal i Giralt, 2000, p. 143-145), així com en les dades obtingudes de la Barcelona Historical Marriage Database publicades pel bisbat de Barcelona (Amengual Bibiloni i Pujadas-Mora 2016).

En el cas del Llenguadoc i la conca del Garona, els bisbats més representats són els d'Agen, amb 118 mencions (un 31,05\% sobre el total de la regió), i Tolosa, amb 97 (representant un 25,53\%).

19. Sobre aquestes relacions a nord i sud dels Pirineus, que es bastia i reproduïa a partir d'un entramat institucional ben característic com les «lligues i patzeries», vegeu els treballs de Patrici Poujade (Poujade 1998, 2008). 
Si analitzem les dades en funció dels bisbats, tenim que els cinc bisbats més representats són Caurs (un 10,20\% de les mencions), Rodés (10,06\%), Agen (8,25\%), Comenge (7,97\%) i Sant Flor (7,90\%).

\section{Taula 3}

\section{Distribució de nuvis occitans per bisbats de procedència (nombres absoluts i percentatges sobre el total)}

\begin{tabular}{|l|l|l|l|l|l|l|l|l|l|l|l|l|}
\hline \multicolumn{9}{|l|}{ Pirineus } & \multicolumn{3}{|l|}{ Llenguadoc i conca del Garona } & \multicolumn{3}{|l|}{ Terres altes i massissos } \\
\hline $\begin{array}{l}\text { ref. } \\
\text { mapa }\end{array}$ & Bisbat & Mencions & $\%$ & $\begin{array}{l}\text { ref. } \\
\text { mapa }\end{array}$ & Bisbat & Mencions & $\%$ & $\begin{array}{l}\text { ref. } \\
\text { mapa }\end{array}$ & Bisbats & Mencions & $\%$ \\
\hline 5 & Alet & 3 & 0.72 & 2 & Agen & 118 & 31.05 & 11 & Caurs & 146 & 23.93 \\
\hline 7 & Baiona & 2 & 0.48 & 4 & Albi & 55 & 14.47 & 24 & Llemotges & 60 & 9.48 \\
\hline 15 & Comenge & 114 & 27.21 & 6 & Auch & 5 & 1.32 & 33 & Perigús & 6 & 0.98 \\
\hline 18 & Coserans & 76 & 18.14 & 9 & Bordeus & 3 & 0.79 & 35 & Rodés & 144 & 23.61 \\
\hline 23 & Lescar & 2 & 0.48 & 12 & Carcassona & 25 & 6.58 & 38 & Sant Flor & 113 & 18.52 \\
\hline 28 & Mirapeix & 56 & 13.37 & 20 & Lavaur & 2 & 0.53 & 39 & Sarlat & 70 & 11.48 \\
\hline 16 & Pàmias & 42 & 10.02 & 22 & Leitora & 11 & 2.9 & 42 & Tula & 71 & 11.64 \\
\hline 34 & Rius & 54 & 12.89 & 25 & Lombés & 36 & 9.47 & 14 & Clarmont & 20 & 0.03 \\
\hline 40 & Tarba & 70 & 16.71 & 31 & Narbona & 19 & 5.00 & 26 & Lió & 2 & 0.003 \\
\hline & & & & 36 & Sant-Papol & 9 & 2.37 & & & & \\
& & & & & & & & & & & \\
\hline & & & & 41 & Tolosa & 97 & 25.53 & & & & \\
\hline & TOTAL & $\mathbf{4 1 9}$ & $\mathbf{1 0 0}$ & & TOTAL & $\mathbf{3 8 0}$ & $\mathbf{1 0 0}$ & & TOTAL & $\mathbf{6 3 2}$ & $\mathbf{1 0 0}$ \\
\hline
\end{tabular}

Font: ADG, Dispenses de Proclames.

La preponderància de les zones més septentrionals d'Occitània com a llocs d'origen de la població establerta a partir del corrent migratori no s'ha documentat en gaires punts de Catalunya, si agafem exemples dispersos de la geografia catalana. En els casos de Nadal i Giralt, les procedències dels immigrants documentats a l'Hospital de la Santa Creu de Barcelona i a la Matrícula de 1637 pertanyen principalment a la zona pirenaica o llenguadociana, en segon terme (on destaca notablement el bisbat de Comenge), i la presència d'immigrants de l'Alta Alvèrnia o Baix Carcí hi són, exceptuant la diòcesi de Caurs, poc representades. Així mateix apareix en el Maresme estudiat per A. Capdevila (Capdevila 2014).

En el cas de la Conca de Barberà, estudiada per Valentí Gual, trobem una gran representació del bisbat de Tarba, situat a la zona dels Pirineus (al costat occidental de Comenge), seguida de la presència de bisbats septentrionals, principalment Clarmont, seguit de Caurs, i finalment es detecta la presència de llenguadocians. Una situació semblant correspon a Lleida, amb una presència destacada de la zona circumpirinenca, sobretot els cen- 


\section{Mapa 3}

Mapa dels bisbats occitans. De groc a vermell, de menys a més nombre de nuvis francesos que declaren provenir-ne

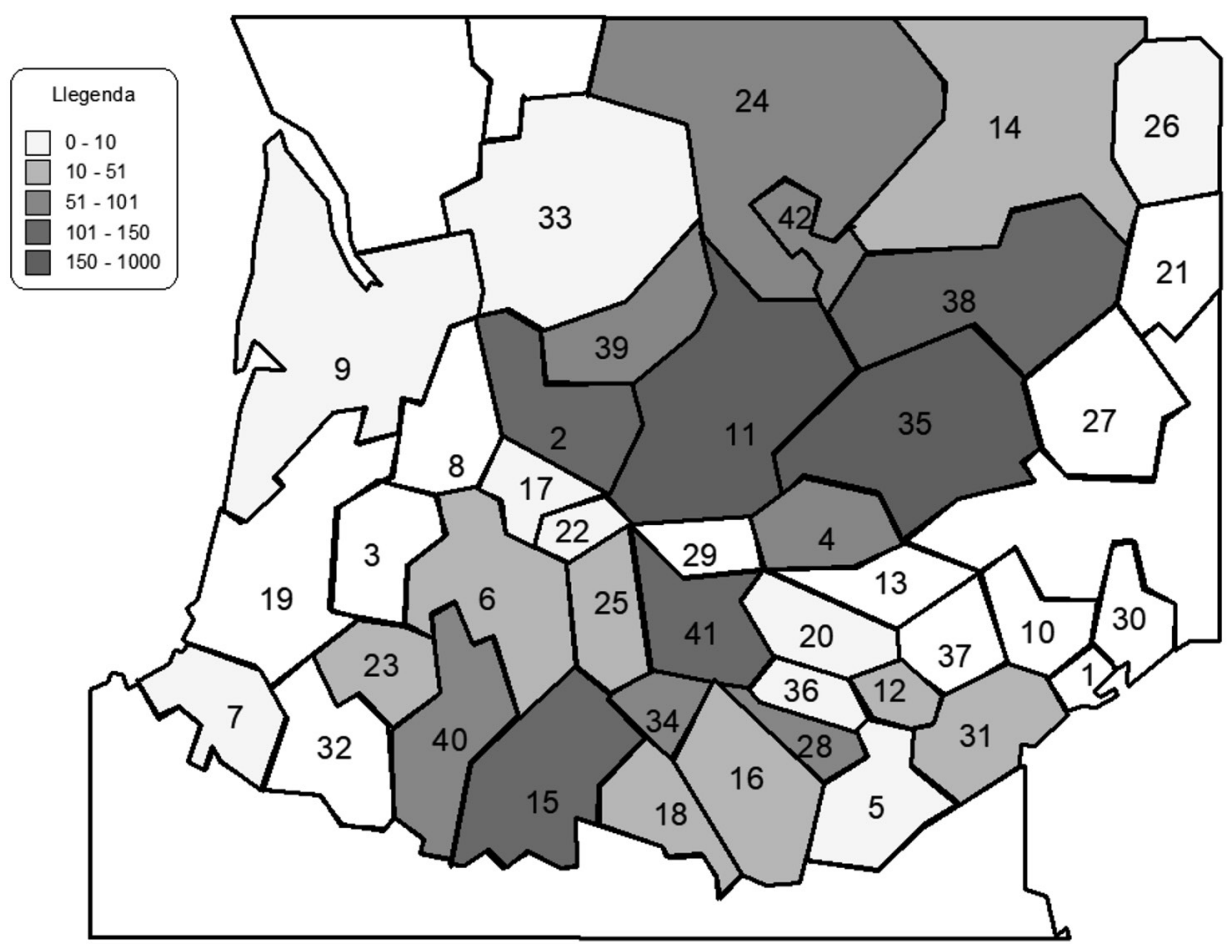

Els números dels bisbats es corresponen amb els de la taula $11 .^{20}$ Font: ADG, Dispenses de Proclames.

tres de Comenge i Tarba i alguns altres com Auloron, Lescar, Rius, Coserans i Pàmias, i, en segon lloc, provinents de la Narbonesa, el Baix Garona i el Llenguadoc; en darrer lloc, els provinents del Massís Central: Llemotges, Caurs, Clarmont i Rodés (Vilalta 2003). Els estudis de Llobet i Portella sobre els registres parroquials de matrimoni de Cervera entre el 1501 i el 1700 també estableixen aquesta escala (zona circumpirinenca, Llenguadoc i finalment Massissos Centrals) (Llobet Portella 1989).

Així doncs, per les dades que proporcionen els registres de Dispenses, al bisbat de Girona hi va predominar un corrent migratori amb origen als bisbats de les Terres Altes i Massissos, especialment els de Caurs, Rodés i Sant-Flor. Val a dir que aquestes dades són solidàries amb les provinents de la Matrícula de 1637. A través del registre de 379 matriculats,

20. Els bisbats en blanc no comptabilitzen cap nuvi que en procedeixi i no apareixen a la taula, es tracta dels bisbats de (1) Agde, (3) Aira, (8) Bazas, (10) Besiers, (13) Castres, (17) Condom, (19) Dax, (21) Lo Puèi, (27) Mende, (29) Montalban, (30) Montpeller, (32) Auloron, (37) Sant Pons. 
els bisbats de les Terres Altes i Massissos tenen una representació del 40,37\% del total, seguits pels de la zona dels Pirineus (29,02\%) i finalment els provinents del Llenguadoc i conca del Garona (25,07\%). Pel que fa al conjunt dels bisbats, Rodés n'és el més representat amb el 14,51\% de mencions, seguit de Sant Flor amb 9,23\%. En el cas de la Matrícula, però, Caurs només representa un 5,54\%, per darrere de bisbats com Comenge $(6,86 \%)$ i Mirapeix $(7,39 \%){ }^{21}$

Alguns d'aquests immigrants van arribar joves, en companyia d'amics i familiars. És el cas de Joan Bastida, testimoni en la dispensa del mestre de cases Joan Burgada, de 30 anys i oriünd de Murat (bisbat de Sant Flor). Segons Bastida, «nos ne vinguerem tots junts de França (...) ahont per tots los divuyt anys havem estat per la costa de la Marina ço és Arenys, Canet, Pineda, Lloret i Tordera». ${ }^{22} \mathrm{Si}$ bé era habitual provenir d'una mateixa parròquia, les xarxes de parents a partir de les quals s'emprenia el procés migratori podien ser més extenses. Un exemple el tenim amb el cas d' Antoni Gay, teixidor de lli resident a Palafrugell. Gay va estar a la Bisbal aprenent l'ofici dos anys i després a Palafrugell. Provinent de la parròquia de Salvaterra (sic.) a Caurs. Tenia 20 anys en el moment de demanar dispensa i en duia 5 al país (hi arribà amb 15 anys). Un dels seus testimonis, Guillem Delpont, resident a la Bisbal, afirma que «lo dit Antoni es nebot meu fill de una germana de ma muller». Si bé tots els testimonis, inclòs el seu oncle, provenien de Caurs, no tots venien de la mateixa parròquia. Guillem provenia de Vilafranca (sic.), així com Esteve Agasses, teixidor de lli, que afirma que fa deu anys que és a Catalunya i coneix «el dit Antoni de petit a casa sons pares d'on marxà per anar a la Bisbal per aprenent ab mi ahont estigué dos anys». ${ }^{23}$

A vegades, els contactes s'havien establert prèviament, principalment a partir de familiars assentats en el territori. És el cas de Pere Morellas, de 30 anys, que hi arribà amb 13 i afirma que «va estar 12 anys continus a casa el meu oncle». Un dels seus testimonis, Joan Pons, treballador, afirmà que «vingueren de França junts del mateix lloo», concretament de la parròquia de Mossach, del bisbat de Caurs. ${ }^{24}$ Una situació similar ens la presenta Antoni Pujol, de 25 anys, i veí de la Bisbal, que arribà a Catalunya amb 7 anys i afirmava que «e estat dos anys en la vila de Perpinyà» i segons un dels seus testimonis: «estigue en casa de mon germà Bernat Gallart de la Bisbal alguns dos anys» $\mathrm{i}$ «en dita vila de la Bisbal ahont estigue alguns dotze anys treballant de offici de pagès i de rajoler». ${ }^{25}$

Val a dir també que aquesta afluència d'immigrants provinents de bisbats alvernesos no era desconeguda a l'època. Així se'ns ha llegat a partir del testimoni del viatger francès

21. Val a dir que algunes dades de la Matrícula per al bisbat de Girona ja han estat presentades en altres treballs (Capdevila 2011; Corredor i Plaja 2000). Pel que fa al litoral empordanès, Alexandra Capdevila troba una forta presència de mencions a Rodés i Sant Flor, on el els provinents de les Terres Altes i Massissos suposen un 35,5\% del total de individus amb procedència documentada (Capdevila 2011), un percentatge deu punts inferior al que ens mostren les Dispenses i molt similar, si bé inferior, al que presentem per al total de confessions de la Matrícula.

22. ADG Dispenses de proclames 1598-1601, p. 288.

23. ADG, Dispenses de proclames 1598-1601, p. 104-105.

24. ADG Dispenses de proclames 1598-1601, p. 66-67.

25. ADG Dispenses de proclames 1598-1601, p. 49-50. 
Joly que passà per Figueres el 1603, el qual afirmà que «tots els artesans allà són francesos de l'Alta Auvèrnia». ${ }^{26}$ La tendència immigratòria dels alvernesos no és pas desconeguda en la historiografia i podria explicar en part aquesta presència tant elevada. ${ }^{27}$ En les causes d'aquesta tendència, els historiadors hi han trobat l'estructura de la propietat, ${ }^{28}$ un règim de treball agrícola marcat per l'estacionalitat, la tipologia de conreus i les institucions familiars, i el règim d'herència. ${ }^{29}$

\section{Conclusions}

Els registres de Dispenses de Proclames representen una font inestimable per elaborar un estudi regional sobre la immigració francesa al bisbat de Girona. Malgrat que no podem avaluar el seu rang d'actuació ni afirmar que tots els matrimonis efectuats per francesos passessin pel bisbat, el fet de tractar-se d'una font que cobreixi el conjunt del que avui són les comarques gironines és de gran ajuda per elaborar una panoràmica general que tingui en compte diversos aspectes diacrònics i espacials. Es demostra especialment interessant per a la recerca l'ús de fonts que cobreixen una àrea heterogènia com el llibre d'esposalles de la catedral de Barcelona (Amengual Bibiloni i Pujadas-Mora 2016) i les mateixes Dispenses, atès que permeten suplir dos dels principals esculls dels registres parroquials: la seva atomització i l'absència de referències a la procedència dels individus registrats. Això sí, és imprescindible que la recerca es faci amb el seu suport. Una de les conclusions del treball del qual aquest article en suposa tan sols un fragment, és que l'ús combinat de diverses fonts és imprescindible per al coneixement d'una realitat complexa com és la de qualsevol fenomen migratori, i especialment en un període del qual encara coneixem tan poc com són els segles xvi i xvII.

Tot i així, l'ús combinat de Dispenses i registres parroquials de matrimoni té una limitació que és la impossibilitat d'atansar-nos als canvis que es van produir durant mitjans segle xvi, període que es considera d'auge del corrent migratori. Els registres matrimonials consultats no van més enllà de 1580 i la sèrie de Dispenses s'inicia el 1593. Una via per complementar aquestes dades seria l'ús dels registres notarials, tot i la seva dificultat com a font en estudis demogràfics.

Tant les dades extretes de la font de Dispenses com dels registres matrimonials, mostren com la immigració francesa al bisbat de Girona segueix les pautes i tendències generals pel que fa a cronologia, ritme i presència dels immigrants francesos. No obstant, cal insistir en el caràcter no homogeni de la immigració que es tradueix en un impacte demo-

26. Referència extreta de Colls, 2002c.

27. Vegeu, entre d'altres, les monografies locals d'Abel Poitrineau (Poitrineau 1983) i Alfred Durand (Durand 1946), antigues però sens dubte ben enfocades a explicar un fenomen que, si bé és ben conegut pel que fa a les zones muntanyenques dels Massissos Centrals, segons els autors es podria extrapolar a altres àrees d'immigració, per exemple els Pirineus.

28. Alfred Durand feia referència al fet que l'emigració expulsava sobretot bracers i mossos (Durand 1946, p. 378-379)

29. I que, segons Poitrineau, «implique l'expulsion postérieure ou antérieure de la plupart des autres enfants, dotés» (Poitrineau 1977). 
gràfic irregular i, tal com hem pogut veure, en diferents pautes d'assentament per part dels immigrants.

Ara bé, aquesta distribució irregular només ens pot estar parlant de l'existència de realitats i processos econòmics i socials diferents arreu del territori. El fet que trobem viles que exerceixen més atracció, com és el cas de Banyoles, Olot i sens dubte la ciutat de Girona en contraposició a regions on la distribució és molt més rural, com l'Empordà, ens podria estar parlant d'alguns fenòmens ja ressenyats per part d'alguns historiadors: la pèrdua d'importància de viles com Castelló d'Empúries, amb una forta indústria baixmedieval (Colls 2002b), i la represa econòmica que sembla detectar-se a d'altres com Girona durant el segle xv. Ara bé, aquests processos no devien suposar a priori un fre o un incentiu pel que fa a l'atracció d'immigrants. El cas del bisbat de Girona mostra que, precisament, les dues àrees que reben més presència immigratòria són el binterland gironí i l'Empordà, que destaca per una pauta d'assentament molt difús, on el total d'immigrants assentats en els nuclis principals de poblament com Castelló d'Empúries, Peralada, Figueres i Roses no superen el 33\% dels francesos documentats a la font de Dispenses. Així doncs, més del 50\% de francesos que, segons la font de Dispenses, hi ha al bisbat de Girona entre 1593-1640, es troben difuminats per un territori que està patint un procés de ruralització.

Els matisos en relació a l'impacte de la migració, que han enriquit recentment i substancialment la recerca sobre aquest fenomen i que hem comentat al llarg del nostre treball, s'han de fer sempre en relació als diferents processos de desenvolupament que es van donar a les diverses àrees del Principat que, com bé assenyala Llorenç Ferrer, no s'expliquen només per l'influx de la ciutat de Barcelona i del litoral (Ferrer i Alòs 2008). Pel cas que ens ocupa, només podem explicar aquesta pauta d'assentament a partir de la vivacitat del camp gironí i del procés de rearticulació agrària que, després de la crisi baixmedieval, va tenir lloc a la Catalunya de masos (Congost et al. 2015; Gifre 2011). Un procés ben estudiat en les comarques de Girona i que va tenir una pota substancial en un procés d'engrandiment patrimonial protagonitzat per algunes famílies remences (Gifre 2003), que van reeixir en la posada en funcionament dels seus patrimonis a partir de la mobilització de força de treball més enllà del nucli familiar mitjançant diverses estratègies, essent la masoveria la més coneguda (Congost, Saguer, Gifre i Torres i Sans 1999), però sense menystenir el paper del jornalerisme i el servei domèstic entre els mossos, molts d'ells, immigrants francesos.

Sens dubte, caldrà posar en relació ambdós fenòmens, per una banda la rearticulació agrària del camp català, del qual la regió de Girona en suposa un dels exemples més evidents pel que fa a les terres de masos, i la immigració francesa, atreta per aquest dinamisme econòmic emmarcat al llarg segle xvı. Deixem aquest exercici, però, per a una propera publicació.

\section{Bibliografia}

Alberch i Fugueras, R. (1984). Gremis i oficis a Girona: treball i societat a l'època pre-industrial. Girona: Ajuntament, Educació i cultura. 
Amengual Bibiloni, M., i Pujadas-Mora, J.-M. (2016). «Orígens i destins de la immigració francesa a l'àrea de Barcelona (1481-1643): aportacions a partir de la Barcelona Historical Marriage Database». Manuscrits: Revista d'història moderna, 2397(34), 35-61.

Busquets Dalmau, J. (1994). La Catalunya del Barroc vista des de Girona. La crònica de Jeroni de Real (1626-1683). Girona: Publicacions de l'Abadia de Montserrat.

Cañabate Fortuño, J. (2018). La batllia de Miravet (segles XVII $i$ XVIII). Demografia, societat i economia. Universitat de Barcelona.

CANYAmeres, E. (1994). «La immigració francesa al Vallès Occidental (s. XVI-XviI): quatre exemples locals: Sabadell, Sant Cugat del Vallès, Sant Julià d'Altura i Sentmenat». Arraona, III(15), 9-25.

CAPDEvila, A. (2003a). «La matrícula de 1637, una radiografia dels francesos residents al Maresme». Annals de l'Institut d'Estudis Gironins, XLIV, 233-246.

Capdevila, A. (2003b). Pagesos, mariners $i$ comerciants a la Catalunya litoral. El Maresme a l'època moderna. Universitat de Barcelona.

Capdevila, A. (2011). «Les característiques de la immigració occitana a l'Alt Empordà abans de 1640».Annals de l'Institut d'Estudis Empordanesos, 217-236. https://doi.org/10.2436/ 20.8010.01.79.

CAPDEvila, A. (2014). Quan la terra promesa era al sud: la immigració francesa al Maresme als segles XVI $i$ XVII. Mataró: Fundació Iluro.

Castells, N. (1994). «L'evolució de la població de la ciutat de Girona durant el segle xvi». Annals de l'Institut d'Estudis Gironins, 34, 81-112.

Codina, J. (1988). Els pagesos de Provençana 984-1807: Societat i economia a l'Hospitalet pre-industrial. L'Hospitalet de Llobregat, Barcelona: Publicacions de l'Abadia de Montserrat.

Colls, J. (2002a). «D'artesans a pagesos l'evolució del treball en una vila de la Catalunya moderna: Castelló d'Empúries, segles xv-Xviı. Treballs de recerca de doctorat (Universitat de Girona. Departament de Geografia, Història i Història de l'Art). Girona: Generalitat de Catalunya. Departament de Cultura.

Colls, J. (2002b). Immigració francesa i repressió a la Catalunya del segle XVI: alguns exemples del Comtat d'Empúries. 35.

Colls, J. (2007). «La transformació de la plana empordanesa en els períodes medieval i modern. El cas de Castelló d'Empúries». Annals de l'Institut d'Estudis Empordanesos, 355-364.

Congost, R., Ferrer i Alòs, L., Lluch, R., Mallorquí, E., Saguer, E., i Gifre, P. (2015). The catalan mas (R. Congost, Ed.). Associació d'Història Rural de les Comarques Gironines.

Congost, R., Portell, J., Saguer, E., i Serramontmany, A. (2013). «Dispensation from banns: A data source for historical demography and social history». Population, 67(3), 549-563.

Congost, R., Saguer, E., Gifre, P., i Torres i Sans, X. (1999). «L'evolució del contracte de masoveria (Girona, s. XV-XvIII)». En Homes, masos, bistòria. La Catalunya del nord-est, SS. $X I-X X$ (p. 269-299).

Corredor i Plaja, A.-M. (2000). «La vida dels francesos residents a la costa del Baix Empordà el 1637». Estudis del Baix Empordà, 19, p. 79-100. 
DanTí i Riu, J. (1986). «El Vallès Oriental a l'època moderna: el creixement demogràfic i econòmic als segles XVI I XvII». Pedralbes: Revista d'bistòria moderna, (6), p. 197-207.

DupÂQuier, J., Sauvy, A. i Le Roy Ladurie, E. (1988). Histoire de la population française. París: Presses universitaires de France.

Durand, A. (1946). La vie rurale dans les Massifs volcaniques des Dores, du Cézallier, du Cantal et de l'Aubrac. Aurillac.

FERRER I Alòs, L. (2008). «La diversitat de l'activitat econòmica a la Catalunya moderna: més enllà de la renda feudal». Pedralbes: revista d'bistòria moderna, 28(28), p. 725-764.

GHirARdi, M. i Irigoyen López, A. (2009). El matrimonio, el concilio de trento e hispanoamérica. Revista de Indias, 246(LXIX), p. 241-272. https://doi.org/10.3989/revindias.2009.020.

Gifre, P. (2003). «La consolidació d'un grup pagès: els senyors útils i propietaris de masos (1486-1730)». Pedralbes: Revista d'bistòria moderna, 23 (1)(2003), p. 513-535.

Gifre, P. (2011). Delmes, censos i lluïsmes. El feudalisme tardà a la Catalunya Vella (Vegueria de Girona, s. XVI-XVII. Girona: ARHCG, Documenta Universitària.

Jané Checa, O. (2009). «De l'expulsió dels jueus i moriscos a les immigracions franceses de l'època moderna». En Els processos migratoris a les terres de parla catalana (p. 201211). València: Publicacions de la Coordinadora de Centres d'Estudis de Parla Catalana.

Llobet Portella, J. M. (1989). «La immigració francesa a Cervera segons els capítols matrimonials conservats a l'Arxiu Històric Comarcal de la ciutat (1501-1700)». Espacio, Tiempo y Forma, Serie IV, $H^{a}$ Moderna, 2, p. 45-62.

Millàs i Castellví, C. (1996). «La immigració francesa al Papiol: 1566-1700». Materials del Baix Llobregat, (2), p. 85-93.

Millàs I CaSTELlví, C. (2005). Els altres catalans dels segles XVI $i$ XVII: la immigració francesa al Baix Llobregat en temps dels Àustria. Barcelona: Publicacions de l'Abadia de Montserrat.

NADAL, J. i GIRALt, E. (1960). La Population catalane de 1553 à 1717: l'immigration française et les autres facteurs de son dévellppement. París: S.E.V.P.E.N.

NadAL, J. i GiRalt, E. (1966). La immigració francesa a Mataró durant el segle XVII. Mataró: Fundació Iluro.

NADAL, J. i GiRALT, E. (2000). Immigració i redreç demogràfic: els francesos a la Catalunya dels segles XVI $i$ XVII. Vic: Eumo.

Peytaví Deixona, J. (2010). Antroponímia , poblament i immigració a la Catalunya moderna. Barcelona: IEC, Treballs de l'Oficina Onomàstica.

Planas, M. (1985). «Vies d'estudi dels registres parroquials. Estructura social i oficis a l'Alt Empordà durant l'Antic Règim». Manuscrits: Revista d'bistòria moderna.

PoitrinEAu, A. (1977). «Sur la configuration des familles en Auvergne aux xvi et XviI siècles». En Entre faim et loup... les problemes de la vie et l'émigration sur les hautes terres françaises au xviIIe siècle (p. 81-93).

Poitrineau, A. (1983). Remues d'hommes. Les migrations montagnardes en France. ParÍs: Aubier.

Possou, J. P. (1988). Mobilité et migrations. En Histoire de la population française (p. 99143). París. 
Poujade, P. (1998). «Les relacions transpirinenques a la Catalunya Moderna: els tractats de "Lligues i Patzeries"»; Pedralbes: revista d'història moderna, (18), 189-199.

Poujade, P. (2008). «La frontera pirinenca i el comerç a l'època moderna». Manuscrits: Revista d'bistòria moderna, 26, 79-91.

Salas Auséns, J. A. (1979). «Los registros parroquiales como fuente para el estudio de la inmigración: franceses en Barbastro entre dos centurias (siglos XVI-XvII)». Argensola: Revista de Ciencias Sociales del Instituto de Estudios Altoaragoneses, 67-84.

Salas Auséns, J. A. (2009). En busca de El Dorado. Inmigración francesa en la España de la Edad Moderna. Bilbao: Universidad del País Vasco.

Silvestre Rodríguez, J. (2000). «Aproximaciones teóricas a los movimientos migratorios contemporáneos: Un estado de la cuestión». Historia Agraria, 21, 157-192.

TORRES i SANS, X. (2006). La Guerra dels Segadors. Lleida: Eumo.

VILALTA, M. J. (2003). «Los franceses en la Lleida moderna. Posibilidades para trabajar, dificultades de inserción». En M. B. Villar García i P. Pezzi Cristóbal (ed.), Los extranjeros en la España Moderna. Actas del I Coloquio Internacional (p. 695-705). Málaga. 